УДК 621.574

\title{
Методика определения термодинамической эффективности абсорб- ционных холодильных установок на основе анализа эксергетических потерь в их элементах
}

\author{
А. С. Титлов ${ }^{1 凶}$, Е.А. Осадчук ${ }^{2}$, Н.А. Биленко \\ Одесская национальная академия пищевых технологий, ул. Канатная, 112, Одесса, 65039, Украина \\ ORCID: ${ }^{1}$ 0000-0003-1908-5713, ${ }^{2}$ 0000-0002-8955-2041 \\ $\triangle$ e-mail: titlov1959@gmail.com
}

\begin{abstract}
Дефицит органических топливных ресурсов, особенно ощутимый в настоящее время в Украине, а также ужесточающиеся во всем мире экологические требования по снижению потенциала глобального потепления на планете ставят как никогда ранее актуальную задачу снижения потребления топлива в энергетических, холодильных и энерготехнологических установках. Рассмотрено два подхода при эксергетическом анализе ичилов холодильных установок. При первом подходе определяют эксергетические КПД отдельных элементов установки, по которым судят о термодинамическом совершенстве проиессов, происходящих в этих элементах, а затем определяют эксергетический КПД всей установки. При втором подходе определяют относительные эксергетические потери, сопоставляют их значения по величине и, затем, по универсальной формуле рассчитывают эксергетический КПД установки. При работе бытовых морозильников от сетевой электроэнергии термодинамические преимущества имеют компрессорные модели. При этом основные потери имеют место при получении и транспортировке электроэнергии (до 70 \%). В абсорбционно-диффузионных моделях холодильных агрегатов значительно возрастают потери в термосифоне-генераторе, однако, ввиду полного отсутствия потери, связанной с получением электроэнергии, общий их эксергетический КПД увеличивается примерно в 3 раза, а, по сравнению с компрессионнылми моделями - в 1,7 раза.
\end{abstract}

Ключевые слова: абсорбиионные водоаммиачные холодильные установки; абсорбиионно-диффузионные холодильные агрегаты; эксергетический анализ; энергетическая эффективность.

\section{Методика визначення термодинамічної ефективності абсорбційних холодильних установок на основі аналізу ексергетичних втрат в їх елементах}

\author{
О. С. Тітлов ${ }^{1}$, Осадчук С.О. ${ }^{2}$, Біленко Н.О.
}

Одеська національна академія харчових технологій, вул. Канатна, 112, Одеса, 65039, Україна

\begin{abstract}
Дефіцит органічних паливних ресурсів, особливо відчутний в даний час в Україні, а також посилення у всьому світі екологічних вимог щзодо зниження потенціалу глобального потепління на планеті ставлять як ніколи раніше актуальне завдання зниження споживання палива в енергетичних, холодильних $і$ енерготехнологічних установках. Розглянуто два підходи при ексергетичному аналізі ицклів холодильних установок. При першому підході визначають ексергетичні ККД окремих елементів установки, за якими судять про термодинамічну досконалість процесів, щзо відбуваються в ичих елементах, а потім визначають ексергетичний ККД всієї установ$\kappa и$. При другому підході визначають відносні ексергетичні втрати, зіставляють їх значення за величиною $i$, потім, за універсальною формулою розраховують ексергетичний ККД установки. При роботі побутових морозильників від мережевої електроенергії термодинамічні переваги мають компресорні моделі. При изьому основні втрати мають місие при отриманні і транспортуванні електроенергї (до 70\%).

У абсорбиійно-дифузійних моделях холодильних агрегатів значно зростають втрати в термосифонігенераторі, однак, зважаючи на повну відсутність втрати, пов'язаної з отриманням електроенергї, загальний їх ексергетичний ККД збільшується приблизно в 3 рази, а, в порівнянні з компресійними моделями - в 1,7 разу.
\end{abstract}

Ключові слова: абсорбція водоаміачні холодильні установки; абсорбиійної-дифузійні холодильні агрегати; ексергетичний аналіз; енергетична ефективність. 


\section{1. Введение}

Оценка термодинамического совершенства реальных процессов в энергетических, холодильных и энерготехнологических установках имеет важное значение, ибо чем термодинамически совершеннее процесс, тем меньше затраты топлива на его осуществление.

Стандартом для сравнения реальных процессов служат идеальные (практически не достижимые) процессы, в которых получаемая механическая работа максимальна, а затрачиваемая - минимальна.

Разность между работой в обратимом и реальном процессах (в случае получения механической энергии) и наоборот (в случае затраты механической энергии) является термодинамической потерей, или потерей эксергии в реальном процессе.

Под эксергией потока рабочего тела понимается та максимальная работа, которая могла бы быть получена теоретически при переходе рабочего тела из данного состояния (характеризующегося параметрами с индексом «1») к состоянию полного равновесия с окружающей средой (характеризующегося параметрами с индексом «0») [1-4].

Эксергия вычисляется как:

$$
e_{1}=\left(i_{1}-i_{0}\right)-T_{0} \cdot\left(s_{1}-s_{0}\right),
$$

где $T_{0}$ - температура окружающей среды; $i_{0}, s_{0}$ - параметры рабочего тела при температуре окружающей среды.

В случае термодинамического цикла для получения механической энергии за счет теплоты $Q_{l}$, подводимой к рабочему телу от горячего источника при температуpe $T$, можно говорить об эксергии этой теплоты. Она будет равна максимальной работе термодинамического цикла, состоящего из обратимых термодинамических процессов, осуществляющихся между горячим источником с температурой $T$ и холодным источником с температурой $T_{0}$. Эксергия этой теплоты, в соответствии с положениями Карно, выразится как [342]:

$$
E_{T}=Q_{1}-T_{0} \int_{1}^{2} \frac{d Q}{T}=Q_{1}-T_{0} \cdot \Delta S_{\text {г }},
$$

где $\Delta S_{\text {г }}$ - изменение энтропии горячего источника при отводе от него теплоты $Q_{1}$.

Эксергия работы тех видов энергии, которые прямо (либо косвенно) теоретически полностью превращаются в механическую энергию, численно равна самой работе этих видов энергии. К ним относятся электрическая энергия или энергия химических связей (последняя теоретически полностью превращается в электрическую энергию в топливных элементах). Таким обра3ом:

$$
\begin{aligned}
& E_{M}=L_{M} ; \\
& E_{\ni}=L_{\ni} ; \\
& E_{X}=L_{M} .
\end{aligned}
$$

Если речь идет об энергии химических связей органического топлива, то, с достаточной точностью, его эксергия $E_{\text {Oт }}$ равна:

$$
E_{O T} \approx b \cdot Q_{p}^{H},
$$

где $b$ - расход топлива; $Q_{p}^{\mu}-$ теплотворная способность топлива.
Термодинамическая (или эксергетическая) потеря $\Pi_{i}$ в каком-либо процессе, который осуществляется в данном элементе установки, вычисляется по формуле Клаузиса [5]:

$$
\Pi_{i}=T_{0} \cdot\left(\sum \Delta s\right)_{i},
$$

где $(\Sigma \Delta s)_{i}$ - сумма изменений энтропии всех тел, участвующих в процессе.

Под эксергетическим КПД $\eta_{e i}$ какого-либо элемента установки, в котором осуществляется данный процесс, понимается отношение:

$$
\eta_{e i}=\frac{\left(\sum E_{\text {вblx }}\right)_{i}}{\left(\sum E_{\text {Bx }}\right)_{i}},
$$

где $\left(\sum E_{\text {выx }}\right)_{i}$ - сумма всех видов эксергии на входе в элемент установки; $\left(\sum E_{6 x}\right)_{i}$ - то же, на выходе из элемента установки.

Очевидна связь между этими величинами:

$$
\eta_{e i}=1-\frac{\Pi_{i}}{\left(\sum E_{6 x}\right)_{i}} .
$$

Под эксергетическим КПД энергетической установки (прямой термодинамический цикл) понимается отношение величины реально полученной электроэнергии $L_{\ni}$ к эксергии того вида энергии, который подведен в установку $E_{6 x}$ :

$$
\eta_{e}^{\ni у}=\frac{L_{\ni}}{E_{6 x}} .
$$

Применительно к энергетической установке на органическом топливе выражение (8) с учетом (4), приобретает вид:

$$
\eta_{e}^{\ni у}=\frac{L_{\ni}}{b \cdot Q_{p}^{\mu}}=\eta_{\ni},
$$

т.е. превращается в обычный, т.н. «электрический» КПД установки.

Под эксергетическим КПД холодильной установки (обратный термодинамический цикл) понимается отношение величины минимально необходимой работы $L_{\min }$ для получения холодильного в диапазоне температур $T_{X} \ldots T_{O}\left(T_{X}-\right.$ температура в холодильной камере) к сумме эксергии всех видов энергии, подведенных в холодильную установку $\Sigma E_{6 x}$, т.е.:

$$
\eta_{e}^{X}=\frac{L_{\min }}{\sum E_{b x}} .
$$

Очевидно, что величина $L_{\min }$ равна работе, затрачиваемой в обратном цикле Карно при верхней температуре $T_{0}$ и нижней температуре $T_{X}$. С учетом всего сказанного, из (10) следует, что:

$$
\eta_{e}^{X}=\frac{Q_{0}}{\sum E_{6 x}} \cdot\left(\frac{T_{0}}{T_{X}}-1\right) .
$$

Применительно к парокомпрессионной холодильной установке, для которой источником энергии является электрическая энергия, выражение (11) с учетом (3), приобретает вид:

$$
\eta_{e}^{X \kappa}=\varepsilon_{\ni} \cdot\left(\frac{T_{0}}{T_{X}}-1\right),
$$

где $\varepsilon_{\ni}=\frac{Q_{0}}{L_{\ni}},-$ эффективный холодильный коэффициент установки. 
Применительно к теплоиспользующим холодильным установкам (абсорбционным и пароэжекторным холодильным установкам), для которых источниками энергии являются тепло невысокого потенциала $Q_{\Gamma}$ и электрическая энергия $L_{\ni H}$, выражение (11) с учетом (2) и (3), приобретает вид:

$$
\eta_{e}^{X T}=\zeta_{T} \cdot \frac{\left(\frac{T_{0}}{T_{X}}-1\right)}{1-\frac{T_{0} \cdot \Delta S_{\Gamma}-L_{\ni H}}{Q_{\Gamma}}},
$$

где $\Delta S_{\Gamma}$ - изменение энтропии источника низкопотенциального тепла; $\eta_{T}=\frac{Q_{0}}{Q_{\Gamma}}-$ тепловой коэффициент холодильной установки.

Для постоянной температуры низкопотенциального источника $T_{\Gamma}=$ const (либо для среднеинтегральной температуры $T_{\Gamma}=\frac{\int_{1}^{2} \frac{d Q}{T}}{\Delta S_{\Gamma}}$ при переменности температуры низкопотенциального источника), выражение (13) с учетом пренебрежимо малой затраты энергии на насосы ввиду несжимаемости жидкости, упрощается и приобретает вид:

$$
\eta_{e}^{X T}=\zeta_{T} \cdot \frac{T_{\Gamma} \cdot\left(T_{0}-T_{X}\right)}{T_{X} \cdot\left(T_{\Gamma}-T_{0}\right)} .
$$

В работе [5] введено понятие об относительной эксергетической потере $\Omega_{i}$, являющейся отношением абсолютной потери $\Pi_{i}$, вычисляемой по формуле (5), к эксергии (либо сумме эксергии), подводимой на входе в установку:

$$
\Omega_{i}=\frac{\Pi_{i}}{E_{B x}}
$$

В работах $[5,6]$ показано, что как для энергетических, так и для холодильных установок, их эксергетические КПД могут быть рассчитаны через относительные эксергетические потери $\Omega_{i}$ как:

$$
\eta_{e}=1-\sum \Omega_{i}
$$

Существуют два подхода при эксергетическом анализе установок.

При первом подходе определяют эксергетические КПД отдельных элементов установки по формулам (1) и (6), сопоставляют их значения, по которым судят о термодинамическом совершенстве процессов, происходящих в этих элементах и, затем, по соотношениям (8), (14) определяют эксергетический КПД всей установки.

При втором подходе по формулам (5), (15) определяют относительные эксергетические потери $\Omega_{i}$, также сопоставляют их значения по величине и, затем, по универсальной формуле (16) рассчитывают эксергетический КПД установки.

Необходимым условием проведения эксергетического анализа установок при любом из подходов является знание всех параметров рабочего тела (включая энтропию) в характерных точках схемы (цикла) установки, которые определяются на основе предварительного теплового расчета.
Оба подхода правомерны, оба базируются на двух началах термодинамики и оба дают идентичные результаты. Выбор того или иного подхода зависит от вкуса и привычек исследователя. Мы отдали предпочтение второму подходу ввиду представляющейся его наглядности и простоты вычислений.

Изложенные общие исходные положения эксергетического анализа установок позволяют перейти к алгоритму эксергетического анализа конкретных схем абсорбционных холодильных установок.

\section{2. Алгоритм эксергетического анализа абсорб- ционных холодильных установок}

Алгоритм эксергетического анализа разрабатывался для двух типов абсорбционных холодильных установок: для установки с электромеханическим насосом для циркуляции водоаммиачного раствора (АХУ) и для абсорбционно-диффузионного холодильного агрегата (АДХА), устанавливаемого в бытовых холодильных приборах.

В состав АХУ входят следующие элементы: генератор, дефлегматор; конденсатор; переохладитель жидкого хладагента; испаритель, помещенный в холодильную камеру; абсорбер; регенеративный теплообменник растворов; водоаммиачный насос и насосы для прокачки охлаждающей воды через дефлегматор, конденсатор и абсорбер; дроссельные вентили для хладагента и для водоаммиачного раствора.

Из предварительных тепловых расчетов [7-8] известны параметры в характерных точках $P_{i}, T_{i}, i_{i}, s_{i}, v_{i}$, расходы рабочего тела через элементы схемы $g_{i}$ (приведенные к расходу хладагента через испаритель), и таким же образом приведенные тепловые нагрузки элементов схемы $q_{i}$, а также приведенная суммарная работа насосов $\Sigma l_{H}$.

Кроме того, известны температура, поддерживаемая в холодильной камере $T_{x}$, температура теплоносителя греющего низкопотенциального источника $T_{\Gamma}=$ const и задана температура окружающей среды $T_{0}$.

При этом эксергия, подведенная к установке, составит:

$\sum E_{\text {вx }}=q \cdot\left(1-\frac{T_{0}}{T_{\Gamma}}\right)+\sum l_{H}=q_{\Gamma}+\sum l_{H}-T_{0} \cdot \Delta S_{\Gamma}^{\prime}$.

где $q_{\Gamma}-$ приведенная тепловая нагрузка генератора.

Далее получим выражения для относительных эксергетических потерь в названных выше элементах схемы.

\section{Генератор}

В процессе генерации водоаммиачного пара участвуют два рабочих тела - кипящий водоаммиачный раствор и теплоноситель греющего низкопотенциального источника. Изменение энтропии кипящего раствора запишется как разность энтропий потоков на выходе из генератора и на входе в генератор:

$$
\Delta S_{K P}=\left(g_{9} \cdot s_{9}+g_{1} \cdot s_{1}\right)-\left(g_{15} \cdot s_{15}+g_{8} \cdot s_{8}\right) .
$$

Изменение энтропии греющего теплоносителя, с учетом постоянства его температуры, составит: 


$$
\Delta S_{\Gamma}=-\frac{q_{\Gamma}}{T_{\Gamma}},
$$

(знак «минус» означает, что тепло отводится и энтропия греющего теплоносителя уменьшается).

Тогда, в соответствии с (5) $\Pi_{\Gamma}=T_{0} \cdot\left(\Delta S_{K P}+\Delta S_{\Gamma}\right)$ и относительная эксергетическая потеря в генераторе, с учетом (15), запишется как:

$$
\Omega_{\Gamma}=\frac{T_{0}}{\sum E_{\theta x}} \cdot\left(g_{1} \cdot s_{1}-g_{8} \cdot s_{8}+g_{9} \cdot s_{9}-g_{15} \cdot s_{15}-\frac{q_{\Gamma}}{T_{\Gamma}}\right)
$$

\section{Дерлегматор}

В процессе охлаждения в дефлегматоре участвуют: рабочее тело и окружающая среда.

Изменение энтропии рабочего тела составит:

$$
\Delta S_{P T}=\left(g_{2} \cdot s_{2}+g_{8} \cdot s_{8}\right)-g_{1} \cdot s_{1} .
$$

Для изменения энтропии окружающей среды, к которой подводится тепло дефлегмации $q_{\partial}$ при температуре $T_{0}$, запишем:

$$
\Delta S_{O C}=\frac{q_{\partial}}{T_{0}} .
$$

При этом относительные эксергетические потери в дефлегматоре составят:

$$
\Omega_{\partial}=\frac{T_{0} \cdot\left(g_{2} \cdot s_{2}+g_{8} \cdot s_{8}-g_{1} \cdot s_{1}-q_{\partial}\right)}{\sum E_{\theta x}} .
$$

\section{Конденсатор и абсорбер}

В процессах конденсации и абсорбции участвуют рабочее тело и окружающая среда. Для относительных эксергетических потерь в конденсаторе и абсорбере по аналогии с (23) запишем:

$$
\begin{gathered}
\Omega_{K}=\frac{T_{0} \cdot g_{3} \cdot\left(s_{3}-s_{2}+q_{K}\right)}{\sum E_{6 x}}, \\
\Omega_{a}=\frac{T_{0} \cdot\left[g_{13} \cdot s_{13}-\left(g_{7} \cdot s_{7}+g_{11} \cdot s_{11}\right)\right]+q_{a}}{\sum E_{6 x}},
\end{gathered}
$$

где $q_{K}$ - приведенная теплота конденсации; $q_{a}$ - приведенная теплота абсорбции.

\section{Переохладитель жидкого хладагента}

Переохладитель жидкого хладагента представляет собой теплообменник, в котором обмениваются теплом жидкий хладагент после конденсатора и парообразный хладагент после испарителя. Изменение энтропии охлаждающегося жидкого хладагента и нагревающегося парообразного хладагента, соответственно, составят:

$$
\begin{aligned}
& \Delta S_{\varkappa}=g_{3} \cdot\left(s_{4}-s_{3}\right), \\
& \Delta S_{n}=g_{6} \cdot\left(s_{7}-s_{6}\right) .
\end{aligned}
$$

При этом относительная эксергетическая потеря в переохладителе жидкого хладагента примет вид:

$$
\Omega_{\text {Пж }}=\frac{T_{0}}{\sum E_{6 x}} \cdot\left[g_{3} \cdot\left(s_{4}-s_{3}\right)+g_{6} \cdot\left(s_{7}-s_{6}\right)\right] .
$$

\section{Регенеративный теплообменник растворов}

В регенеративном теплообменнике растворов обмениваются теплом слабый и крепкий водоаммиачные растворы. Для относительной эксергетической потери в регенеративном теплообменнике растворов по аналогии с (28) запишем:

$$
\Omega_{T P}=\frac{T_{0}}{\sum E_{6 x}} \cdot\left[g_{9} \cdot\left(s_{10}-s_{9}\right)+g_{14} \cdot\left(s_{15}-s_{14}\right)\right] \text {. }
$$

\section{Холодильная камера}

В холодильной камере, в которой установлен испаритель, происходит теплообмен между охлаждаемым при температуре $T_{x}$ объектом и испаряющимся жидким хладагентом. Изменение энтропии охлаждаемого объекта (от него тепло отводится, и энтропия охлаждаемого объекта уменьшается) равно:

$$
\Delta S_{o x}=-\frac{q_{0}}{T_{x}}
$$

где $q_{0}$ - приведенная холодопроизводительность установки.

Изменение энтропии хладагента составит:

$$
\Delta S_{x a}=g_{6} \cdot\left(s_{6}-S_{5}\right) .
$$

При этом относительная эксергетическая потеря в холодильной камере выразится как:

$$
\Omega_{X K}=\frac{T_{0}}{\sum E_{6 x}} \cdot\left[g_{6} \cdot\left(s_{6}-s_{5}\right)-\frac{q_{0}}{T_{x}}\right] .
$$

\section{Дроссельные вентили}

В них относительные эксергетические потери составят:

- в ДВ-1 (жидкий аммиак):

$$
\Omega_{\not B-1}=\frac{T_{0}}{\sum E_{6 x}} \cdot g_{4} \cdot\left(s_{5}-s_{4}\right),
$$

- в ДВ-2 (водоаммиачный раствор):

$$
\Omega_{\not B-2}=\frac{T_{0}}{\sum E_{6 x}} \cdot g_{10} \cdot\left(s_{11}-s_{10}\right) .
$$

Отметим, что, так как дросселирование в ДВ-2 проходит полностью в области жидкой фазы водоаммиачного раствора, т.е. без фазового перехода, то значения энтропии $s_{11}$ и $s_{10}$ весьма близки (практически $s_{11} \approx s_{10}$ ). Поэтому потерей $\Omega_{Д в-2}$ можно пренебречь.

\section{Hacocbl}

Относительные эксергетические потери в насосах зависят от КПД насоса $\eta_{н}$ и КПД электродвигателя $\eta_{ә}$ и могут быть вычислены по формуле:

$$
\Omega_{H}=\frac{\sum g \cdot v_{\varkappa} \cdot \Delta P_{H}}{\sum E_{\theta x}} \cdot\left(\frac{1}{\eta_{H} \cdot \eta_{\partial д}}-1\right),
$$

где $g$ - приведенный расход жидкости через насос; $v_{ж}-$ удельный объем жидкости; $\Delta P_{H}$ - перепад давлений, развиваемый в насосе.

Ввиду несжимаемости жидкости и относительно не высокого перепада давлений потерей $\Omega_{н}$ при эксергетическом анализе, как и при расчетах цикла, пренебрегают.

После определения по формулам (20), (23)...(25), (28), (32)...(35), относительных эксергетических потерь в элементах схемы, определяем по универсальной формуле (16) эксергетический КПД АХУ.

Перейдем теперь к анализу схемы АДХА. В ее состав входят термосифон-генератор, конденсатор, абсорбер, дефлегматор, регенеративный теплообменник 
растворов, холодильная камера с трехпоточным испарителем. Отсутствуют водоаммиачный насос, насосы для прокачки охлаждающей воды и дроссельные вентили.

Как и для АХУ, предполагается, что предварительно проведен тепловой расчет схемы, в результате которого определены параметры в характерных точках $P_{i}, T_{i}, i_{i}, s_{i}$, $v_{i}$, расходы рабочего тела через элементы схемы $g_{i}$, а также приведенные тепловые нагрузки элементов схемы $q_{i}$. Заданы температура охлаждаемого объекта $T_{x}$ и температура окружающей среды $T_{0}$.

Источником энергии для АДХА является электрическая энергия $e_{\text {эл }}$, подаваемая на нагревательный элемент термосифона, которая, с учетом коэффициента потерь в окружающую среду $K_{o c}$, составляет:

$$
e_{э l}=\frac{q_{T C}}{1-K_{o c}},
$$

где $q_{T C}-$ приведенная тепловая нагрузка термосифона $T C$, известная из предварительного теплового расчета схемы.

Величина $e_{\text {эл }}$, в соответствии с равенствами (3), будет равна эксергии на входе в АДХА, т.е.:

$$
\sum E_{b x}=\frac{q_{T C}}{1-K_{o c}}
$$

Поскольку дефлегматор, конденсатор и регенеративный теплообменник растворов а АДХА работают в условиях, аналогичных условиям в АХУ, относительные эксергетические потери в них вычисляются по аналогичным формулам типа (23), (24) и (29), соответственно.

Рассмотрим потери в остальных элементах схемы АДХА

\section{Термосифон-генератор}

Рассмотрим сначала абсолютные эксергетические потери в термосифоне-генераторе. Они складываются из трех составляющих:

- потери в окружающую среду $\Pi_{T C l}$ :

$$
\Pi_{T C 1}=\frac{q_{T C} \cdot K_{o c}}{1-K_{o c}}
$$

- потери при переходе электрической энергии в теплоту, идущую на нагрев металла нагревательного элемента до его средней температуры $T_{M}$; она равна разности между подводимой теплотой $q_{T C}$ и работой цикла Карно, осуществляющегося между средней температурой металла $T_{M}$ и темпера-турой окружающей среды $T_{0}$, т.e.:

$$
\Pi_{T C 2}=q_{T C}-q_{T C} \cdot\left(1-\frac{T_{0}}{T_{M}}\right)=T_{0} \cdot \frac{q_{T C}}{T_{M}}
$$

Учитывая, что отношение $\frac{q_{T C}}{T_{M}}$ представляет собой увеличение энтропии металла нагревательного элемента $\Delta s_{M}$, окончательно можно записать:

$$
\Pi_{T C 2}=T_{0} \cdot \Delta s_{M}
$$

- потери от неравновесного теплообмена между металлом нагревательного элемента и кипящим водоаммиачным раствором, равные:

$\Pi_{T C 3}=T_{0} \cdot\left\{\left[\left(g_{2} \cdot s_{2}+g_{17} \cdot s_{17}\right)-\left(g_{3} \cdot s_{3}+g_{1} \cdot s_{1}\right)\right]-\Delta S_{M}\right\}$.
В формуле (41) изменение энтропии металла нагревательного элемента отрицательное, т.к. от него отводится теплота.

Просуммировав все три вида потерь и разделив эту сумму на эксергию на входе в установку, для относительной эксергетической потери в термосифонегенераторе окончательно получим:

$\Omega_{T C}=\frac{\frac{q_{T C} \cdot K_{o c}}{1-K_{o c}}+T_{0} \cdot\left[\left(g_{2} \cdot s_{2}+g_{17} \cdot s_{17}\right)-\left(g_{1} \cdot s_{1}+g_{3} \cdot s_{3}\right)\right]}{\sum E_{b x}}$.

Из соотношений (38)...(42) следует, что относительные эксергетические потери в термосифонегенераторе не зависят от температуры металла нагревательного элемента $T_{M}$ - она влияет лишь на перераспределение составляющих потерь $\Pi_{T C 2}$ и $\Pi_{T C 3}$.

\section{Холодильная камера}

В холодильной камере установлен трехпоточный испаритель, в котором, кроме производства искусственного холода, осуществляется регенеративное охлаждение бедной парогазовой смеси и переохлаждение жидкого хладагента.

По аналогии с АХУ, для относительной эксергетической потери в холодильной камере АДХА запишем:

$$
\Omega_{X К}=\frac{T_{0}}{\sum E_{6 x}} \cdot\left[g_{10} \cdot s_{10}-\left(g_{6} \cdot s_{6}-g_{9} \cdot s_{9}\right)-\frac{q_{0}}{T_{x}}\right] .
$$

При определении энтропии обедненной $\left(s_{9}\right)$ и обогащенной $\left(s_{10}\right)$ парогазовой смеси, состоящей из паров аммиака и инертного газа гелия (либо водорода) используем свойство аддитивности энтропии, на основании которого:

$$
s_{c M}=\xi \cdot s_{N_{3}}+s_{И \Gamma} \cdot(1-\xi),
$$

где $\xi$ - массовая концентрация смеси по аммиаку; $s_{N H 3}-$ энтропия паров аммиака при температуре, равной температуре паров аммиака, и давлении, равном парциальному давлению паров аммиака в смеси; $s_{\text {Иг }}-$ энтропия инертного газа при температуре, равной температуре паров аммиака, и давлении, равном парциальному давлению инертного газа в смеси.

Учитывая близость свойств гелия и водорода к свойствам идеального газа, энтропия инертного газа может быть, с достаточной точностью, подсчитана по формуле:

$$
s_{\text {ИГ }}=c_{p} \cdot \ln \frac{T}{T_{н}}-R \cdot \ln \frac{P}{P_{u}},
$$

где $c_{p}$ - изобарная теплоемкость инертного газа; $R-$ индивидуальная газовая постоянная инертного газа; $T$ и $P$ - температура смеси и парциальное давление инертного газа, соответственно; $T_{H}$ и $P_{H}-$ нормальные условия, принятые за начало отсчета энтропии, $T_{H}=273,15 \mathrm{~K} ; P_{H}=1,0136 \cdot 10^{5}$ Па.

Значения энтропии паров аммиака в формулах типа (44) и переохлажденной жидкости в (43), взятые по справочным данным [9], следует также привести к нормальным условиям.

\section{Абсорбер}

По аналогии с АХУ, для относительной эксергетической потери в абсорбере АДХА запишем: 
$\Omega_{a}=\frac{T_{0} \cdot\left[\left(g_{11} \cdot s_{11}+g_{14} \cdot s_{14}\right)-\left(g_{12} \cdot s_{12}+g_{13} \cdot s_{13}\right)\right]+q_{a}}{\sum E_{6 x}}$,

где энтропии компонентов рабочего тела в соответствующих точках вычисляются так же, как для испарителя холодильной камеры.

Эксергетический КПД АДХА вычисляется по универсальной формуле (16).

\section{3. Результаты сравнительного эксергетическо- го анализа абсорбционно-диффузионных и компрессорных бытовых холодильных агрега- тов}

Приведенная выше методика позволяет провести сравнительный эксергетический анализ аппаратов бы- товой холодильной техники, в частности, абсорбционно-диффузионных и компрессорных морозильников емкостью $V=200$ дм $^{3}$ (в дальнейшем АД-М и КМ, соответственно).

Принципиальная схема холодильного агрегата для АД-М (рисунок 1) соответствует опытному морозильнику Васильковского завода холодильников.

Она предусматривает регенерацию тепла водоаммиачного пара крепким раствором в ректификационном участке (PУ) термосифона- генератора $T$ - $C$, что приводит к сокращению энергозатрат на $~ 30 \%$ по сравнению с вариантами без ректификации. Ректификация учитывалась при расчете параметров в характерных точках схемы, представленных в таблице 1.

Термодинамические параметры компрессионной схемы в характерных точках представлены в таблице 2.

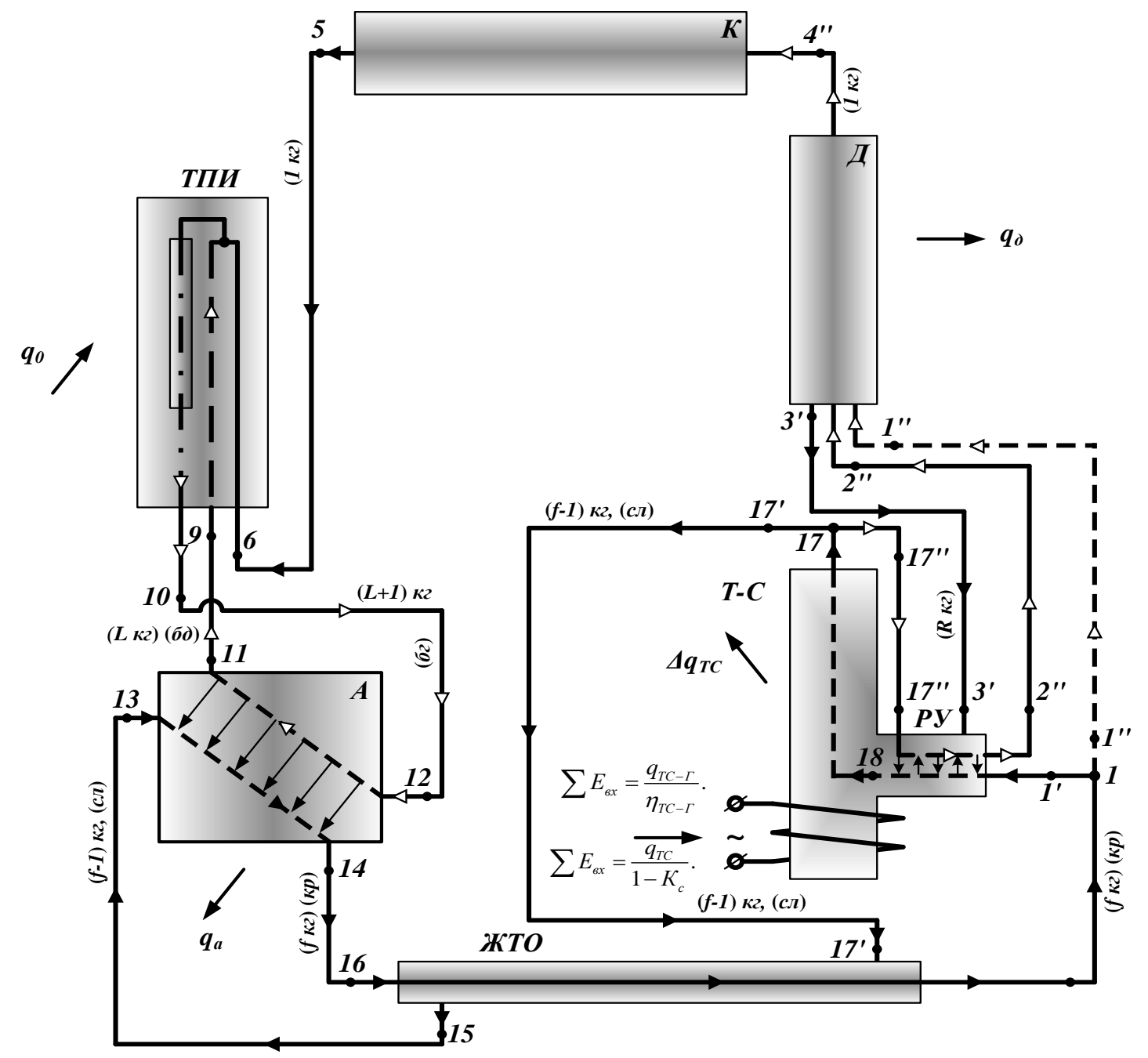

$T$-C - термосифон-генератор с ректификационным участком $P У$; Д- дефлегматор; $K$ - конденсатор; ТПИ - трехпоточный испаритель; $A$ - абсорбер; ЖТО - жидкостный регенеративный теплообменник. [линия $\left(1^{\prime \prime}-1^{\prime \prime}\right)$ - тогда, когда $i_{1}{ }^{\prime}>i_{1}{ }^{\prime}\left(P ; \xi^{\prime}=\xi_{\text {кp }}\right)$ ]

Рисунок 1 - Схема холодильного абсорбционно-диффузионного агрегата АД-М 


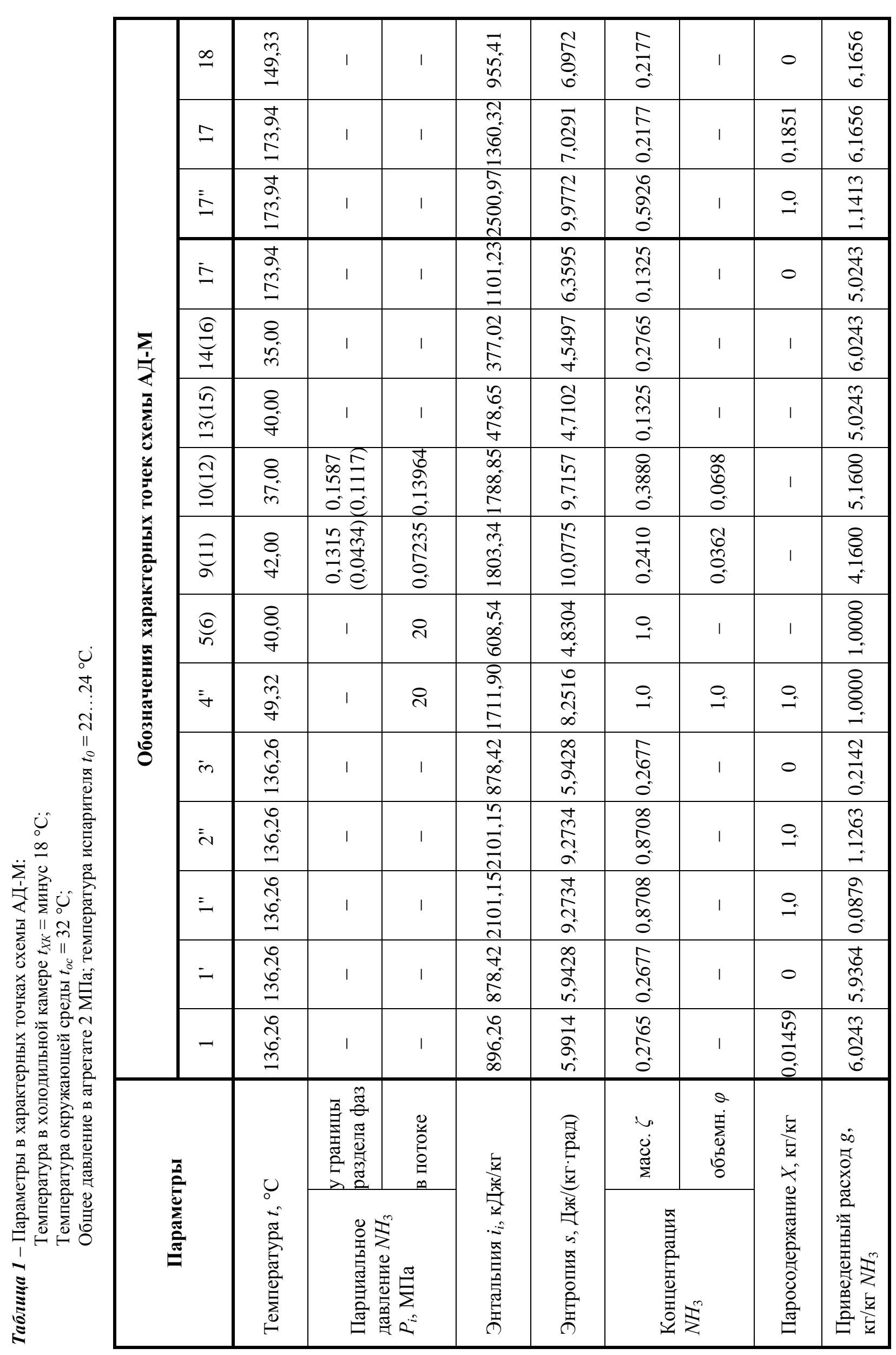




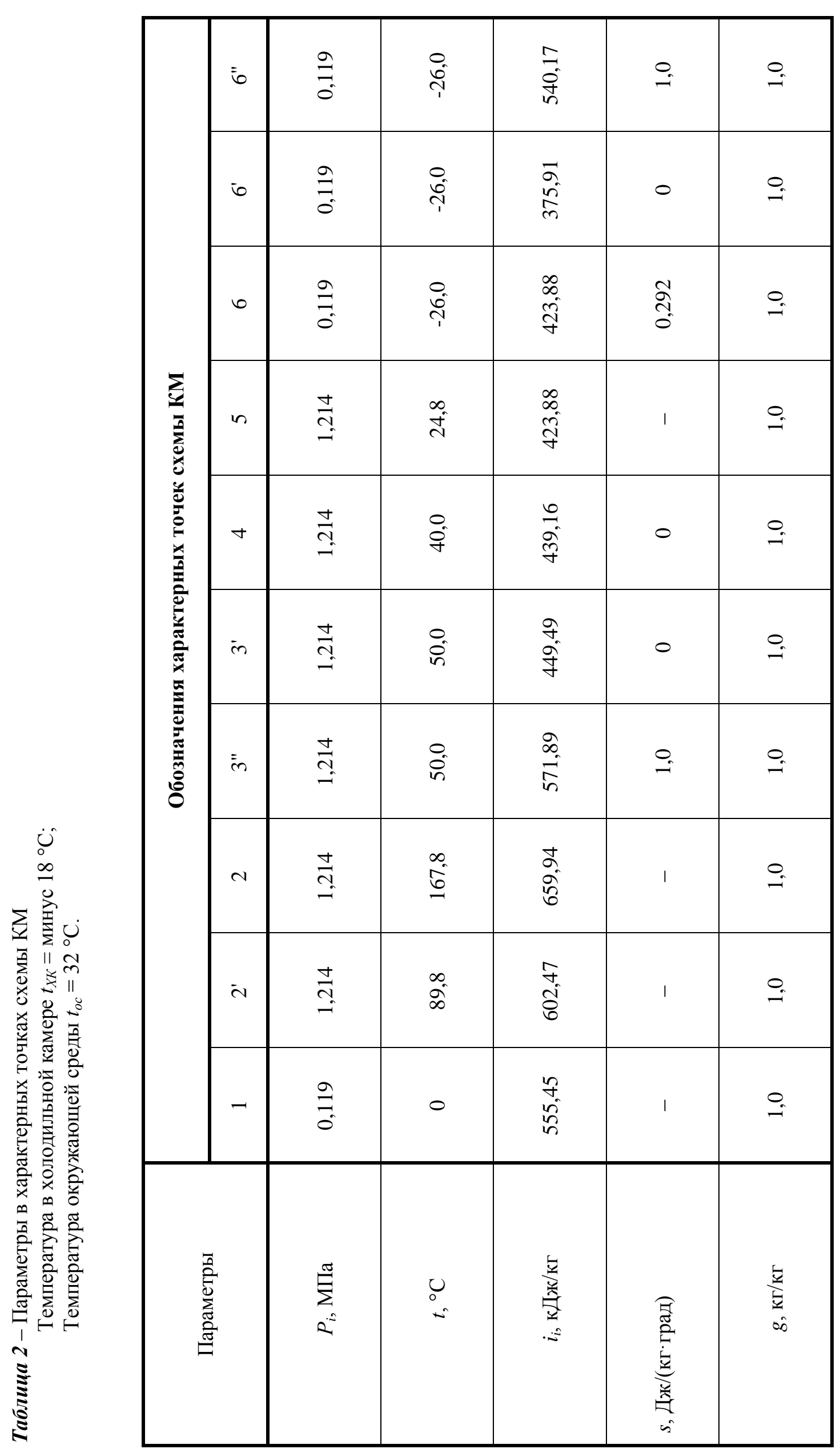


При расчетах параметров схем принято:

\section{Рабочие тела:}

- для АД-М: хладагент - аммиак; нейтральный газ водород;

- для КМ: хладагент - R134a.

\section{Для холодильного агрегата АД-М:}

Температурные напоры:

- максимальный в холодильной камере:

- минимальный в холодильной камере:

- максимальный в конденсатоpe:

- минимальный в конденсато-

pe:

- минимальный в абсорбере между водоаммиачным раствором и окружающей средой: - минимальный в абсорбере между ПГС и раствором:

- на «холодном» конце ЖТО

- минимальный в дефлегматоpe

$\Delta t_{1 X K}=t_{X K}-t_{0 H}=10^{\circ} \mathrm{C} ;$

$\Delta t_{2 X K}=t_{X K}-t_{0 B}=6{ }^{\circ} \mathrm{C} ;$

$\Delta t_{1 K}=t_{4^{\prime \prime}}-t_{0}=17,32^{\circ} \mathrm{C}$;

$\Delta t_{2 K}=t_{5}-t_{0}=8^{\circ} \mathrm{C}$

$\Delta t_{2 a}=t_{14}-t_{0}=3{ }^{\circ} \mathrm{C}$

$\Delta t_{\text {агж }}=t_{12}-t_{14}=$

$=t_{11}-t_{13}=2{ }^{\circ} \mathrm{C}$;

$\Delta t_{\text {ЖTO }}=t_{15}-t_{16}=5{ }^{\circ} \mathrm{C}$;

$\Delta t_{2 \partial}=t_{4^{\prime \prime}}-t_{0}=17,32^{\circ} \mathrm{C}$.

Относительные движущие напоры парциальных давлений $\mathrm{NH}_{3}$ у границы раздела фаз:

- в испарителе в начале испарения:

$$
\begin{gathered}
\varepsilon_{1 u}=\frac{P_{0 \mu}-P_{б \partial}}{P_{0 \mu}}=0,45 ; \\
\varepsilon_{2 u}=\frac{P_{0 \varepsilon}-P_{6 z}}{P_{0 в}}=0,12 ; \\
\varepsilon_{1 a}=\frac{P_{б \partial}-P_{1 a}}{P_{б \partial}}=0,4 ; \\
\varepsilon_{2 a}=\frac{P_{6 z}-P_{2 a}}{P_{6 z}}=0,2 .
\end{gathered}
$$

крепкого раствора:

- концентрация пара $\mathrm{NH}_{3}$ на выходе из дефлегматоpa: $\xi_{4^{\prime \prime}} \approx 1$;

- коэффициент тепловых потерь от термосифонагенератора в окружающую среду: $K_{o c}=0,05 \ldots 0,14$.
Принято также, что температура флегмы на выходе из дефлегматора равна температуре пара на входе в него, а температура этого пара на выходе из ректификационного участка термосифона-генератора равна температуре крепкого раствора на входе в ректификационный участок. Таким образом, соблюдается приблизительное равенство:

$$
t_{1}=t_{2^{\prime \prime}}=t_{3^{\prime}}
$$

Для КМ:

КПД герметичного мотор-компрессора: индикаторный: $\quad \eta_{i}=0,45$; механический: $\quad \eta_{M}=0,7$; электрический: $\quad \eta_{\text {эл }}=0,8$.

Температура пара R134а на выходе из PTO: $t_{1}=0^{\circ} \mathrm{C}$.

Приведенные исходные данные получены на основании паспортных и справочных данных, а также - на основании экспериментальных исследований, проведенных в ОНАПТ [10-12].

На основе данных таблицы 1 и таблицы 2 были рассчитаны удельные (на 1 кг хладагента) тепловые нагрузки морозильников $q_{i}$ и показатели их энергетической эффективности: тепловой коэффициент $\zeta_{T}-$ для $A Д-M$ и эффективный холодильный коэффициент $\varepsilon_{э \phi}-$ для KM. Полученные данные представлены в таблице 3. Они показывают, что если энергия $q_{T C}$ и $l_{\text {эл }}$ в обоих типах морозильников подводится в виде сетевой электроэнергии, то $K M$ имеют безусловное энергетическое преимущество - в 1,7 раза.

Однако, следует учесть, что АД-М, в отличие от КМ, могут работать не только от сетевой электроэнергии, но и от теплоты сгорания топлива, сжигаемого в топочном устройстве, установленном непосредственно в морозильнике. Поэтому сравнительный эксергетический анализ проводился для обоих возможных вариантов:

- первый - АД-М и КМ работают от сетевой элек-

\begin{tabular}{|c|c|c|c|c|c|c|}
\hline \multirow{2}{*}{$\begin{array}{l}\text { 吉 } \\
\text { 임 }\end{array}$} & \multirow{2}{*}{\multicolumn{2}{|c|}{ Наименование термодинамических показателей }} & \multirow{2}{*}{ 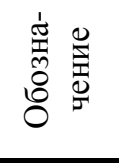 } & \multirow{2}{*}{ 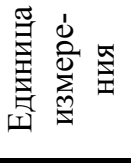 } & \multicolumn{2}{|c|}{ Численное значение } \\
\hline & & & & & АД-М & KM \\
\hline 1 & \multicolumn{2}{|c|}{ Холодопроизводительность } & $q_{0}$ & кДж/кг & 939,64 & 116,29 \\
\hline 2 & \multicolumn{2}{|c|}{ Подводимая энергия } & $q_{T C}, l_{э л}$ & кДж/кг & 2628,03 & 186,59 \\
\hline 3 & \multirow{5}{*}{ Тепловая нагрузка } & конденсатора & $q_{K}$ & кДж/кг & 1103,24 & 220,78 \\
\hline 4 & & $\begin{array}{l}\text { ректификационного } \\
\text { участка }\end{array}$ & $q_{P y}$ & кДж/кг & 487,83 & - \\
\hline 5 & & дефлегматора & $q_{\partial}$ & кДж/кг & 651,06 & - \\
\hline 6 & & абсорбера & $q_{a}$ & кДж/кг & 1681,97 & - \\
\hline 7 & & $\begin{array}{l}\text { жидкостного регенера- } \\
\text { тивного теплообменника }\end{array}$ & 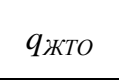 & кДж/кг & 3128,03 & - \\
\hline 8 & \multicolumn{2}{|c|}{ Теплопотери в окружающую среду } & $\Sigma \Delta q_{\text {nom }}$ & кДж/кг & 131,40 & 82,10 \\
\hline 9 & \multicolumn{2}{|c|}{ Тепловой коэффициент } & $\zeta_{T}$ & $\%$ & 35,75 & - \\
\hline 10 & \multicolumn{2}{|c|}{ Тепловая нагрузка регенеративного теплообменника } & $q_{P T O}$ & кДж/кг & - & 15,28 \\
\hline 11 & \multicolumn{2}{|c|}{ Эффективный холодильный коэффициент } & $\varepsilon_{כ \phi}$ & $\%$ & - & 62,32 \\
\hline
\end{tabular}
троэнергии;

- второй - АД-М работает от горелочных устройств, а КМ работает от сетевой электроэнергии.

Tаблица 3 - Удельные тепловые нагрузки аппаратов и показатели энергетической эффективности морозильников 
В целях общности подхода первичной энергией считалась химическая энергия топлива. В первом варианте и для АД-М и для КМ - это доля топлива, сжигаемая на электростанциях со среднестатистическим КПД ее получения и транспортировки $\bar{\eta}_{\ni}$; во втором - для КМ - это тоже топливо, сжигаемое на электростанциях, а для АД-М - это топливо, сжигаемое в горелочных устройствах с КПД этих горелочных устройств $\bar{\eta}_{z y}$.

При проведении сравнительного эксергетического анализа относительные эксергетические потери в элементах цепи преобразования энергии рассчитывались по формуле (15), в которой эксергия на входе в термодинамическую систему (эксергия органического топлива, практически равная его теплотворной способности) вычислялась как:

- при работе АД-М и КМ от сетевой электроэнергии:

$$
E_{6 x}^{K M}=\frac{l}{\bar{\eta}_{\ni}} ; \quad\left(E_{6 x}^{\text {Ад }}\right)^{\prime}=\frac{q_{T C}}{\bar{\eta}_{\ni}} ;
$$

- при работе АД-М от горелочных устройств:

$$
\left(E_{6 x}^{\text {АДМ }}\right)^{\prime \prime}=\frac{q_{T C}}{\bar{\eta}_{Г У}}
$$

где $l_{\text {эл }}$ - удельная энергия, подведенная к моторкомпрессору КМ;

$q_{T C}$ - удельная энергия, подведенная к термосифонугенератору в АД-М.

Эксергетический КПД всей системы преобразования энергии определялся по формуле (16).
При расчетах принято: среднестатистический КПД получения и транспортировки электроэнергии (в условиях Украины) $\bar{\eta}_{э}=0,3$; усредненный КПД горелочных устройств $\bar{\eta}_{z y}=0,86$.

Результаты сравнительного эксергетического анализа представлены в таблице 4.

\section{Выводы}

Анализ полученных результатов показывает, что бытовые морозильники являются термодинамически несовершенными устройствами - эксергетические КПД преобразования энергии при их работе не превышают 7 $\%$.

При работе бытовых морозильников от сетевой электроэнергии термодинамические преимущества, как и следовало ожидать, имеют компрессорные модели. При этом основные потери имеют место при получении и транспортировке электроэнергии $\left(\Omega_{n э}=70 \%\right)$.

Для абсорбционно-диффузионных моделей, в отличие от компрессорных моделей, имеется способ улучшить эксергетические показатели путем использования в качестве источника энергии органического топлива. При этом значительно возрастают потери в термосифоне-генераторе, однако, ввиду полного отсутствия потери, связанной с получением электроэнергии, общий эксергетический КПД АД-М увеличивается в 3 раза, а, по сравнению с КМ - в 1,7 раза. Во столько же раз уменьшается расход первичного топлива, что весьма существенно в условиях Украины.

Tаблица 4 - Результаты сравнительного эксергетического анализа систем преобразования энергии

\begin{tabular}{|c|c|c|c|c|c|}
\hline \multirow{2}{*}{\multicolumn{2}{|c|}{ Наименование потерь в элементах систем }} & \multirow{2}{*}{ 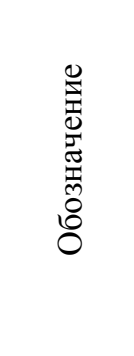 } & \multirow{2}{*}{ 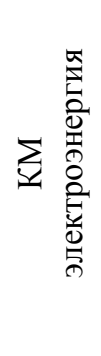 } & \multicolumn{2}{|c|}{ АД-М } \\
\hline & & & & 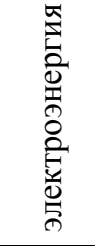 & 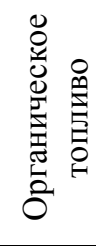 \\
\hline \multicolumn{2}{|c|}{ При получении и транспортировке электроэнергии } & $\Omega_{n \ni}, \%$ & 70,00 & 70,00 & - \\
\hline \multirow{3}{*}{ Мотор-компрессор } & индикаторные & $\Omega_{i}, \%$ & 7,03 & - & - \\
\hline & механические & $\Omega_{M}, \%$ & 7,20 & - & - \\
\hline & электрическе & $\Omega_{э, l}, \%$ & 6,00 & - & - \\
\hline \multirow{4}{*}{ Термосифон-генератор } & в окружающую среду & $\Omega_{o c}, \%$ & - & 1,50 & - \\
\hline & в горелочных устройствах & $\Omega_{2 y}, \%$ & - & - & 14,00 \\
\hline & при генерации пара & $\Omega_{2 n}, \%$ & - & 20,02 & 60,40 \\
\hline & в ректификационном участке & $\Omega_{p y}, \%$ & - & 0,36 & 1,00 \\
\hline \multicolumn{2}{|l|}{ В морозильной камере } & $\Omega_{M K}, \%$ & 0,73 & 1,96 & 6,00 \\
\hline \multicolumn{2}{|c|}{ В конденсаторе } & $\Omega_{K}, \%$ & 3,94 & 0,69 & 2,10 \\
\hline \multicolumn{2}{|c|}{ В регенеративном теплообменнике } & $\Omega_{\text {pmo }}, \%$ & 0,50 & 1,40 & 4,20 \\
\hline \multicolumn{2}{|c|}{ От дросселирования } & $\Omega_{\partial p}, \%$ & 0,94 & - & - \\
\hline \multicolumn{2}{|l|}{ В абсорбере } & $\Omega_{a}, \%$ & - & 0,57 & 1,80 \\
\hline \multicolumn{2}{|c|}{ В дефлегматоре } & $\Omega_{\partial \phi}, \%$ & - & 1,40 & 4,20 \\
\hline \multicolumn{2}{|c|}{ Эксергетический КПД системы } & $\eta_{e \kappa}, \%$ & 3,66 & 2,10 & 6,30 \\
\hline
\end{tabular}
при работе КМ и АД-М. 


\section{Литература}

1. Шаргут Я., Петела Р. Эксергия. - М., Энергия, 1968 $-280 \mathrm{c}$.

2. Бродянский В.М. Эксергетический метод термодинамического анализа. - М., Энергия, 1973. - 243 с.

3. Андрюшенко А.И. Основы технической термодинамики реальных процессов. - М., Высшая школа, 1975. $175 \mathrm{c}$.

4. Костянко Г.Н. Эксергетический анализ тепловых процессов и установок. - Одесса, Изд. ОПИ, 1964. - 184 c.

5. Гохштейн Д.П. Современные методы термодинамического анализа энергетических установок. - М., Энергия, 1969. $-115 \mathrm{c}$.

6. Промышленность Украины: Путь к энергетической эффективности // ЕC - Energy Center, Kiev, Ukreine, 1995. - 199 c.

7. Захаров М.Д. Енергетичні і екологічні показники компресійної та абсорбційної побутової холодильної техніки / М.Д.Захаров, О.С. Тітлов, Ю.С. Ботук, О.Б. Василів, Н.В. Рева // Наукові праці Одеської державної академії харчових технологій. - 1997. - № 17. - С. 167 175.

8. Ботук Ю.С. Экспериментальное определение экономичности низкотемпературной камеры с абсорбционно-диффузионными холодильными машинами на различных температурных уровнях замораживания /
Ю.С. Ботук, А.С. Титлов, О.Б. Васылив // Тепловые режимы и охлаждение радиоэлектронной аппаратуры. Научно-технический сборник. -1998. - № 1. - С. 68-70.

9. Богданов С.Н., Иванов О.П., Куприянова А.В. Холодильная техника. Свойства веществ -Изд. 3-е перераб. и доп. -М.: Агропромиздат, 1985. -208 с.

10. Ботук Ю.С. Экспериментальное определение экономичности низкотемпературной камеры с абсорбционно-диффузионными холодильными машинами на различных температурных уровнях замораживания / Ю.С. Ботук, А.С. Титлов, О.Б. Васылив // Тепловые режимы и охлаждение радиоэлектронной аппаратуры. Научно-технический сборник. -1998. - № 1. - С. 68-70. 11. Захаров М.Д. Аналіз ексергетичної ефективності циклів АДХМ / М.Д. Захаров, О.С. Тітлов, Д.С. Тюхай, Ю.С. Ботук, О.Б. Василів // Наукові праці Одеської державної академії харчових технологій. - 2001. - № 22. - C. 161-167.

12. Тітлов О.С. Науково-технічні основи створення енергозберігаючих побутових абсорбційних холодильних приладів / О.С. Тітлов, М.Д. Захаров // Наукові праці Одеської національної академії харчових технологій. - 2009. - № 35. - Т.1. - С. 113-127.

13. Железный В.П., Жидков В.В. Экологоэнергетические аспекты внедрения альтернативных хладагентов в холодильной технике. - Донецк: Донбас, 1996. $-144 \mathrm{c}$.

\title{
Method for determining the thermodynamic efficiency of absorption cooling plants based on the analysis of exergy losses in their elements
}

\author{
O. S. Tstlov ${ }^{l \otimes}$, E. O. Osadchuk. ${ }^{2}$, N.A. Bilenko \\ Odesa National Academy of Food Technologies, 112 Kanatna str., Odesa, 65039, Ukraine \\ $\triangle$ e-mail: titlov1959@gmail.com
}

The deficit of organic fuel resources, especially tangible now in Ukraine, as well as the increasingly stringent global environmental requirements to reduce the global warming potential on the planet, put the actual task of reducing fuel consumption in energy, refrigeration and energy technology plants as never before. The prerequisite for solving this problem at the stage of research and development is a theoretical analysis of losses from the irreversibility of processes in the elements of energy, refrigeration and energy technology facilities (exergy losses) and the search for practical ways to reduce these losses, which provide fuel savings. Two approaches are considered in the exergy analysis of facilities. At the first approach, the exergic efficiency of the individual plant elements is determined, by which the thermodynamic perfection of the processes occurring in these elements is judged, and then the exergic efficiency of the entire installation is determined. In the second approach, the relative exergetic losses are determined, their values are compared in magnitude, and then, using the universal formula, the exergy efficiency of the installation is calculated. The analysis of the obtained results showed that household freezers are thermodynamically imperfect devices - the exergy energy conversion efficiency at their work does not exceed $7 \%$. When household freezers operate from grid electricity, compressor models have thermodynamic advantages. At the same time, the main losses occur in the receipt and transportation of electricity (up to $70 \%$ ). For absorption-diffusion models, unlike compressor models, there is a way to improve exergy indicators by using fossil fuels as a source of energy. At the same time, losses in the thermosyphon generator significantly increase, however, in view of the total absence of the loss associated with the production of electric power, their total exergy efficiency increases approximately 3-fold, and, in comparison with the compression models, by a factor of 1,7.

Keywords: absorption water-ammonia refrigeration units; absorption-diffusion refrigeration units; exergy analysis; energy efficiency.

\section{References}

1. Shargut Ya., Petela R. Eksergiya. - M., Energiya, 1968. -280 s. (in Russian)

2. Brodyanskiy V.M. Eksergeticheskiy metod termodinamicheskogo analiza. - M., Energiya, 1973. - 243 s. (in Russian)
3. Andryushenko A.I. Osnovyi tehnicheskoy termodinamiki realnyih protsessov. - M., Vyisshaya shkola, 1975. 175 s. (in Russian)

4. Kostyanko G.N. Eksergeticheskiy analiz teplovyih protsessov i ustanovok. - Odessa, Izd. OPI, 1964. - 184 s. (in Russian) 
5. Gohshteyn D.P. Sovremennyie metodyi termodinamicheskogo analiza energeticheskih ustanovok. - M., Energiya, 1969. - 115 s. (in Russian)

6. Promyishlennost Ukrainyi: Put k energeticheskoy effektivnosti // ES - Energy Center, Kiev, Ukreine, 1995. - 199 s. (in Russian)

7. Zaharov M.D. EnergetichnI I ekologIchnI pokazniki kompresIynoYi ta absorbtsIynoYi pobutovoYi holodilnoYi tehnIki / M.D.Zaharov, O.S. TItlov, Yu.S. Botuk, O.B. VasilIv, N.V. Reva // NaukovI pratsI OdeskoYi derzhavnoYi akademIYi harchovih tehnologIy. - 1997. No. 17. - S. 167-175. (in Ukrainian)

8. Botuk Yu.S. Eksperimentalnoe opredelenie ekonomichnosti nizkotemperaturnoy kameryi s absorbtsi-onnodiffuzionnyimi holodilnyimi mashinami na razlichnyih temperaturnyih urovnyah zamorazhivaniya / Yu.S. Botuk, A.S. Titlov, O.B. Vasyiliv // Teplovyie rezhimyi i ohlazhdenie radioelektronnoy apparaturyi. Nauchnotehnicheskiy sbornik. -1998. - No. 1. - S. 68-70. (in Russian)

9. Bogdanov S.N., Ivanov O.P., Kupriyanova A.V. Holodilnaya tehnika. Svoystva veschestv -Izd. 3-e pererab. i dop. -M.: Agropromizdat, 1985. 208 s. (in Russian)
10. Botuk Yu.S. Eksperimentalnoe opredelenie ekonomichnosti nizkotemperaturnoy kameryi s absorbtsi-onnodiffuzionnyimi holodilnyimi mashinami na razlichnyih temperaturnyih urovnyah zamorazhivaniya / Yu.S. Botuk, A.S. Titlov, O.B. Vasyiliv // Teplovyie rezhimyi i ohlazhdenie radioelektronnoy apparaturyi. Nauchnotehnicheskiy sbornik. -1998. - No. 1. - S. 68-70. (in Russian)

11. Zaharov M.D. AnalIz eksergetichnoYi efektivnostI tsiklIv ADHM / M.D. Zaharov, O.S. TItlov, D.S. Tyuhay, Yu.S. Botuk, O.B. VasilIv // NaukovI pratsI OdeskoYi derzhavnoYi akademIYi harchovih tehnologIy. - 2001. No.22. - S. 161-167. (in Ukrainian)

12. TItlov O.S. Naukovo-tehnIchnI osnovi stvorennya energozberIgayuchih pobutovih absorbtsIynih holodilnih priladIv / O.S. TItlov, M.D. Zaharov // Naukovi pratsi OdeskoYi natsIonalnoYi akademIYi harchovih tehnologIy. - 2009. - No. 35. - T.1. - S. 113-127. (in Ukrainian)

13. Zheleznyiy V.P., Zhidkov V.V. Ekologoenergeticheskie aspektyi vnedreniya alternativnyih hladagentov v holodilnoy tehnike. - Donetsk: Donbas, 1996. - 144 s. (in Russian) 